\title{
Principais sistemas de captação de água de chuva: uma forma de diminuir os efeitos das secas prolongadas no município de Lagoa do Ouro, Pernambuco
}

\author{
Main rainwater harvesting systems: a way to reduce the effects of prolonged \\ droughts in the Lagoa do Ouro country, State of Pernambuco' Brazil
}

\section{RESUMO}

Atualmente há necessidade de gerir os recursos hídricos integrando aspectos de captação e armazenamento, pois ambos constituem fatores limitantes ao desenvolvimento socioeconômico, interferindo na saúde pública, no meio ambiente e na economia. A captação e o armazenamento de água de chuva é uma solução alternativa de abastecimento para amenizar os efeitos da seca e prevenir situaçóes de colapso. Neste contexto, o presente trabalho objetivou conhecer os principais sistemas de captação e armazenamento de água de chuva do programa "Água Para Todos" do Governo Federal, utilizado pelos agricultores do município de Lagoa do Ouro, Pernambuco. As metodologias empregadas foram pesquisas bibliográficas, de campo e de informaçóes obtidas na Secretaria de Agricultura do município. O estudo despertou a consciência de que estamos longe de solucionar o problema da "seca do Nordeste", mas temos plena consciência de que existe um esforço dirigido das políticas em âmbito municipal, estadual e nacional no sentido de reduzir, até onde possível, os efeitos dos períodos de estiagem com implantaçóes de tecnologias simples e de baixo custo: construçôes de cisternas, açudes e barragens, bomba d'água popular e reservatórios cilíndricos que podem ser construídos próximos da própria casa da família, visando melhoria nas condiçôes de vida da populaçáo rural de Lagoa do Ouro.

Palavras-chave: Educação ambiental. Recursos hídricos. Extensão universitária. Sustentabilidade. Desenvolvimento regional.

\begin{abstract}
Currently there is a need to manage water resources integrating aspects of capture and storage, as both are limiting factors to socioeconomic development, interfering in the public health, the environment and the economy. Rainwater harvesting and storage is an alternative supply solution to mitigate the effects of drought and prevent collapse. In
\end{abstract}

Antônio Ricardo Santos de Andrade

Doutor em Agronomia (Irrigação e Drenagem) pela Universidade Estadual Paulista "Júlio de Mesquita Filho", São Paulo, Brasil; professor associado II da Unidade Acadêmica de Garanhuns (UAG) da Universidade Federal Rural de Pernambuco, Pernambuco, Brasil. (ricoarsa@gmail.com).

Gustavo Mendes Pinheiro

Graduação em Agronomia pela Universidade Federal Rural de Pernambuco, Pernambuco, Brasil. E-mail: gustavo@gmail.com

Emylle Kerolayne Palmeira de Andrade

Graduanda em Engenharia Civil na Autarquia do Ensino Superior de Garanhuns (AESGA), Pernambuco, Brasil. (emylle@gmail.com).

Marília Karine Silva Santos

Graduanda em Agronomia na Universidade Federal Rural de Pernambuco, Unidade Acadêmica de Garanhuns (UAG), Pernambuco, Brasil. (karinemk65@hotmail.com).

Kerollaynne Badéga Freire Campelo

Graduanda em Agronomia na Universidade Federal Rural de Pernambuco, Unidade Acadêmica de Garanhuns (UAG), Pernambuco, Brasil. (kerolfreire.agro@gmail.com). 
this context, the present work aimed to know the main rainwater harvesting and storage systems of the "Água Para Todos" (Water For All) program of the Federal Government used by farmers in the municipality of Lagoa do Ouro, State of Pernambuco, Brazil. The methodologies used were bibliographical, field and information research obtained at the Secretary of Agriculture of the municipality. The study has raised awareness on our distance from solving the "Drought of the Northeast" problem, but we are fully aware that there is a concerted effort at the municipal, state and national levels to reduce, as far as possible, effects of drought periods with simple and low cost technologies: cistern constructions, dams, popular water pump and cylindrical reservoirs that can be built close to the family home, aiming to improve the lives of the rural population of Lagoa do Ouro.

Keywords: Environmental education. Water resources. University extension. Sustainability. Regional development.

\section{INTRODUÇÃO}

A água é um recurso natural que merece grande importância, pois, mantê-la em condiçóes ideais é fundamental para vida no planeta. Devido os seres humanos explorar os recursos hídricos de forma não sustentável, estes estão se tornando cada vez mais escassos, causando sérios problemas na esfera ambiental, social e econômica principalmente na Região do Semiárido do Nordeste. Assim, se faz necessário adotar alternativas para captação da água de chuva, porém, nem todos os métodos aliados aos programas de governo são viáveis para determinadas regiôes. Em regiôes semiáridas, não só há a necessidade de captar água, como também de armazenar e proteger, para que náo haja perdas elevadas, visando que as chuvas são irregulares, ocorrendo em certo período do ano e deixando o outro período com uma grande escassez hídrica.

O risco da agricultura dependente de chuva e a falta de água para consumo humano e pequenas criaçóes constituem as principais causas da baixa qualidade de vida no meio rural, principalmente nas zonas áridas e semiáridas. O semiárido brasileiro, em sua realidade de enfrentamento às adversidades climáticas, traduzidas em 
longos períodos de estiagens, de insuficiência de investimentos em infraestrutura e em ampliação do acesso às políticas sociais, configurase em uma das regiốes mais pobres do país. Na superação da visão de que seria necessário realizar obras contra as secas e oferecer socorro nas situaçóes de flagelo, um novo conceito, o de convivência com a seca, foi inserido na perspectiva de elaboração de políticas públicas que garantam sustentabilidade ambiental, social e econômica.

Durante a última década, várias ONGs e organizaçóes populares que trabalham no Semiárido Brasileiro (SAB) enfatizaram os sistemas de captação de água de chuva que podem dar uma contribuição essencial para a convivência do povo com o clima semiárido. Uma conscientização sobre as possibilidades da região semiárida está sendo desenvolvida. Já que uma principal necessidade é uma educação apropriada em todos os níveis, muitas organizaçóes trabalhando no $\mathrm{SAB}$ aplicam seus esforços nela. As organizaçôes populares náo só ensinam tecnologias apropriadas, mas falam primeiro sobre uma compreensão adequada do clima semiárido, depois introduzem sistemas de captação de água de chuva e prestam atenção nas condiçôes socioeconômicas e culturais do povo envolvido.

Dentre as concepçôes adotadas, aquela que provavelmente mais apresenta coerência política considera a convivência com a seca, focada nas pessoas, com manejo sustentável, tecnologias apropriadas e de baixo custo, com construções de cisterna-calçadão, cisterna-enxurrada, açudes, barreiro-trincheira, tanque de pedra ou caldeirão, bomba d'água popular, reservatórios cilíndricos que podem ser construídos próximos da própria casa da família e sistema de aproveitamento dos rejeitos da dessalinização das águas subterrâneas, que possibilitem geração de trabalho, renda e qualidade de vida.

Alinhada a esta alternativa, faz-se necessário discutir, elaborar e implementar políticas públicas de convivência com a seca. Nessa perspectiva, um dos órgãos responsáveis pelo setor da agropecuária e abastecimento do município é a Secretaria de Agricultura de Lagoa do Ouro, órgão responsável pela coordenação e execução dos Programas Municipais e também de vários Programas do Governo Federal para o campo, principalmente os voltados para a agricultura familiar, cuja missão é "investir no ser humano e transformar o semiárido". O setor foi constituído para atuar na execução de açôes locais nas comunidades 
de agricultura familiar e nos assentamentos da reforma agrária, visando à incorporação de práticas sustentáveis que possibilitem a convivência com as adversidades inerentes ao semiárido e que pudesse orientar a construção das políticas públicas em questão.

Visando conhecer um pouco do que é realizado nesse setor agropecuário, o projeto está organizado a partir de uma estrutura de técnicos e gestores na Secretaria de Agricultura de Lagoa do Ouro, no período de 6 de abril de 2015 à 16 de junho de 2015. Esse projeto foi baseado no acompanhamento da rotina das pessoas envolvidas na respectiva secretaria, tanto nas atividades de campo como nas de escritório, sob a supervisão da Secretária de Agricultura. O que se pretende aqui é refletir sobre as aprendizagens que a vivência participativa das famílias beneficiárias constrói na vida cotidiana e de como elas articulam os processos organizativos e produtivos. No contexto da participação, compreender como tem influenciado no resgate e vivência de valores e princípios que venham a reforçar a organização, trazendo elementos sobre a construção do protagonismo dos sujeitos.

O presente trabalho objetivou conhecer os sistemas de captação de águas de chuva já instalados do programa Água Para Todos, do Governo Federal, e avaliar as áreas de captaçáo nas residências, assim como registrar as principais fontes de água usadas por comunidades $\mathrm{da}$ área rural do município de Lagoa do Ouro no Estado de Pernambuco. Além disto, o trabalho está focado na questão da participação da sociedade civil e na ação do municipal, estadual e nacional enquanto executora de projetos e programas de beneficio ao produtor: Programa Água para Todos, Programa da Operação Carro Pipa e Programa de Aquisiçấo de Alimentos (PAA).

\section{FUNDAMENTAÇÃO TEÓRICA}

A implantaçáo dessas alternativas vem aperfeiçoar a utilização dos escassos recursos financeiros disponíveis, reduzindo o uso de carros-pipa e as frentes de trabalho, até hoje acionadas no combate às estiagens que, além de dispendiosas, não passam de medidas paliativas (LOPES et al., 2002). Sendo uma ação conjunta dos órgãos governamentais municipais, estaduais e federais, assim como das 
ONG's e das comunidades rurais, essas tecnologias são viabilizadas totalmente por órgãos financiadores de projetos. Todavia, tem sempre a contrapartida dos beneficiários em mão-de-obra e outros recursos locais (LOPES et al., 2002; MARTINS; NOGUEIRA, 2015).

A solução do problema da "seca do nordeste" está longe de ser alcançada. Por isso, os brasileiros devem ter plena consciência de que se houver um esforço dirigido dos políticos em repassar recursos financeiros para os órgáos públicos de pesquisa e extensáo, para em conjunto desenvolverem tecnologias simples e de baixo custo, bem como programarem ações de fortalecimento da infraestrutura social e produtiva, pode-se alcançar a melhoria da qualidade de vida da população rural (LOPES et al., 2002; MARTINS; NOGUEIRA, 2015). As principais alternativas tecnológicas desenvolvidas são: Cisterna rural, Cisterna-calçadão, Cisterna-enxurrada, Barragem subterrânea, Tanque de pedra ou caldeirão, Bomba d'água popular, Barreiro-trincheira, Barraginha, entre outras (ALBUQUERQUE; DURÃES, 2008).

- Cisternas de placa de 16 mil litros: reservatórios cilíndricos, construídos próximo à casa da família. Elas armazenam a água da chuva que cai no telhado que é levada para dentro da cisterna por meio de calhas de zinco e canos de PVC. A construção é de domínio dos agricultores/as de comprovada eficiência técnica. Os pedreiros, inclusive, são agricultores/ as capacitados/as pelas organizaçóes da ASA (Articulação Semiárido Brasileiro);

- Cisterna-calçadão: tecnologia que capta a água da chuva por meio de um calçadão de cimento construído sobre o solo, com aproximadamente $220 \mathrm{~m}^{2}$. Com essa área, $300 \mathrm{~mm}$ de chuva são suficientes para encher a cisterna, que tem capacidade para 52 mil litros. O calçadão também é usado para secagem de alguns grãos como feijão, milho, raspa de mandioca, entre outros;

- Cisterna-enxurrada: tecnologia social que serve para armazenar a água da chuva e tem ajudado a melhorar a qualidade de vida de muitas famílias agricultoras no Semiárido brasileiro. O terreno é utilizado como área de captação. Para a filtragem da água são utilizados dois tanques de decantação. É construída 
dentro da terra, ficando somente a cobertura de forma cônica acima da superfície;

- Barragem subterrânea: importante, principalmente, para o reuso da água na agricultura (BRITO, 1999). Essa técnica de armazenar água da chuva no subsolo tem como função interceptar o fluxo de água superficial e subterrâneo através de uma parede (septo impermeável) construída transversalmente à direção das águas;

- Tanque de pedra ou caldeirão: tecnologia comum em áreas de serra ou onde existem lajedos, que funcionam como área de captação da água de chuva. São fendas largas, barrocas ou buracos naturais, normalmente de granito. $\mathrm{O}$ volume de água armazenado vai depender do tamanho e da profundidade do tanque. É uma tecnologia de uso comunitário. Em geral, cada tanque, beneficia 12 famílias. A água armazenada é utilizada pelas famílias para o consumo dos animais, plantaçóes e nos afazeres domésticos, como lavar roupas;

- Bomba d'água popular: essa técnica aproveita os poços tubulares desativados para captar a água subterrânea por meio de um equipamento manual, que contém uma roda volante. Nos poços com profundidade de $40 \mathrm{~m}$, chega a puxar até 1.000 litros de água em uma hora. É uma tecnologia de uso comunitário, de baixo custo e fácil manuseio. A água da bomba tem vários usos: produzir alimentos, dar de beber aos animais e ser usada nos afazeres domésticos. Geralmente, cada bomba, beneficia 12 famílias;

- Barreiro-trincheira: são tanques longos, estreitos e fundos escavados no solo. Tem esse nome porque se parece muito com uma trincheira. Serve para armazenar a água da chuva, matar a sede dos animais e, também, para que a família possa ampliar a sua área produtiva com verduras, legumes e frutas que ajudarão na alimentação e melhoria da saúde;

- Barraginha: tem entre 2 e 3 metros de profundidade, com diâmetros que variam de 12 a 30 metros. É construída no formato de uma concha ou semicírculo. $\mathrm{O}$ reservatório armazena água da chuva por dois a três meses, possibilitando 
que o solo permaneça úmido por um maior período (PRINZ, 2001). De acordo com Barros (2003) esta forma de captação de água surgiu devido ao "Projeto Barraginhas", desenvolvido pela Embrapa Milho e Sorgo, em Sete Lagoas, Minas Gerais, a partir do ano de 1995, que revolucionou as comunidades rurais mineiras, levando para regiốes com problemas de erosão e ausência de chuvas uma tecnologia que auxilia na recuperaçáo do solo e revitaliza manancial e córregos.

\section{METODOLOGIA}

\section{Localização da pesquisa}

O presente estudo foi desenvolvido entre fevereiro e dezembro de 2015, no município de Lagoa do Ouro, localizado na Mesorregiấo do Agreste e na Microrregião do Município de Garanhuns no Estado de Pernambuco, limitando-se a norte com o município de Brejáo, a sul com o estado de Alagoas, a leste com o município das Correntes, e a oeste com o município de Bom Conselho, distante $275,7 \mathrm{~km}$ da capital, cujo acesso é feito pela BR-101; PE-126/177/187, e BR-424.

O município de Lagoa do Ouro possui uma população de 12.132 habitantes predominantemente rurais, ou seja, $51 \%$ da população, 6.103 pessoas, residem na zona rural, e 50\%, 6.029 pessoas, residem na zona urbana. O município é formado pelos distritos de Igapó e Campo Alegre. A economia local se compóe basicamente dos setores de serviço, do comércio e dos setores da agropecuária (IBGE, 2015). A Secretaria de Agricultura tem o objetivo de atender as necessidades referentes à agricultura e o abastecimento do município. A Secretaria realiza os serviços de vários programas do Governo Federal, Estadual e Municipal, tais como: Programa de Aquisição de Alimentos (PAA), Distribuição de Água Através de Caminhão Pipa, Programa Garantia Safra e Aração de Terra. 
Figura 1 - Foto da sede da prefeitura de Lagoa do Ouro, Pernambuco, 2015.

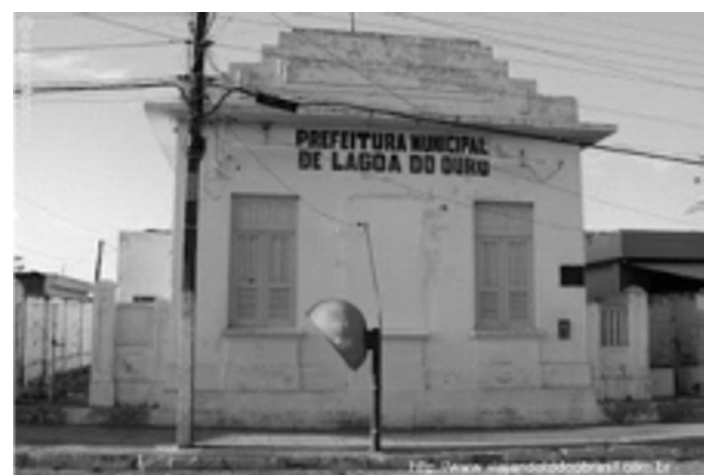

Fonte: Gustavo Mendes Pinheiro (2015).

\section{População e amostra}

Foram visitadas as propriedades de agricultores do município de Lagoa do Ouro, Pernambuco. Para a determinação do tamanho da amostra, foi seguida a metodologia apresentada em Barbetta (2004) e Gil (2000), levando-se em consideração o coeficiente de variação (\%) obtido pelas diversas variáveis analisadas em levantamento piloto envolvendo propriedades, e o nível de significância de 5\% de probabilidade com uma margem de erro de $10 \%$.

Para realização desse estudo, foram acompanhadas ao acaso, 68 famílias no período de janeiro a dezembro de 2015 , localizadas no semiárido do município de Lagoa do Ouro. Desse total, 4 não possuem programas para captação e acumulação de água em suas residências. Após a seleção das famílias, foi realizado um levantamento nas comunidades junto a cada uma delas para identificação da existência de cisternas rurais em suas residências e das fontes de água utilizadas pelos agricultores. Foram realizadas visitas mensais às comunidades para o acompanhamento da captação e acumulação de água nas cisternas, barreiros e cacimbas, como também, das cisternas e residências abastecidas por carros-pipa. Além disso, foi aplicado um questionário às famílias selecionadas, segundo as variáveis socioeconômicas: sexo, faixa etária, grau de escolaridade e renda, e a questão sobre o uso de tecnologia para captação da água da chuva para consumo humano e nas atividades agrícola. 


\section{Coleta e tratamento dos dados}

Os dados foram elaborados e classificados de forma sistemática após a sua coleta. A partir do material coletado (questionário), fez-se a tabulação e análise dos dados. Para que os dados fossem compreendidos, verificados e analisados, foram utilizadas técnicas da estatística descritiva para permitir a visualização geral das atividades de campo e de escritório realizadas na Secretaria de Agricultura do Município de Lagoa do Ouro, com o objetivo de se conhecer as questôes da participação dos agricultores e da ação do estado enquanto executora de projetos e programas de benefício ao produtor, mas também verificar a intensidade do uso de tecnologia, como construçóes de cisterna-calçadáo, cisterna-enxurrada, açudes, barreiro-trincheira, tanque de pedra ou caldeirão, bomba d'água popular, reservatórios cilíndricos que podem ser construídos próximos da própria casa da família e sistema de aproveitamento dos rejeitos da dessalinizaçáo das águas subterrâneas, pelos agricultores para minimizar a seca do município e aprofundar a discussão sobre o tema da agricultura de precisão na regiáo.

\section{RESULTADOS}

\section{Principais programas públicos de benefício ao produtor}

\section{Programa água para todos do Governo Federal}

O Programa Água para Todos integrou o Plano Brasil Sem Miséria e foi idealizado para universalizar o acesso a água entre a populaçâo rural do semiárido brasileiro. $\mathrm{O}$ objetivo é garantir o amplo acesso à água para as populaçóes rurais dispersas e em situaçáo de extrema pobreza, seja para o consumo próprio ou para a produção de alimentos e a criação de animais. Com isso, espera-se que as famílias beneficiadas possam melhorar suas condiçóes de vida, facilitando o acesso à água para consumo humano e evitando que despendam grande parte do dia em longas caminhadas em busca de água, melhorando assim a qualidade da água e a sua preservação, dando a família condiçôes de usufruir deste bem com boa qualidade, contribuindo também para 
a garantia da Segurança Alimentar e Nutricional.

O programa é coordenado pelo Ministério da Integração Nacional e têm entre seus objetivos instalar 750 mil cisternas de abastecimento. Além da implantação de cisternas, o Programa também espera contribuir com a integração União, Estados, Municípios e Sociedade Civil na implementaçáo de açóes que visam à convivência com o semiárido. A cisterna é uma tecnologia milenar e pode responder aos parâmetros de qualidade e quantidade da água para beber das famílias de comunidades onde haja limitação de recursos hídricos, desde que sejam seguidos os critérios de dimensionamento, armazenamento e manejo da água coletada da chuva. Além da melhoria na qualidade da água consumida, a cisterna reduz o aparecimento de doenças em adultos e crianças, eleva a autoestima dessa população e promove a dignidade e a cidadania, um direito de todos (MACEDO, 2004; CODEVASF, 2007).

Segundo LIBERAL et al., (1999), no ano de 1995 foram construídas 1.000 cisternas de placas pré-moldadas no município de Petrolina, sendo, até o momento, considerado como o maior programa de construçáo de cisternas executado por um governo municipal no Nordeste brasileiro. Todavia, esse programa não atendeu a algumas comunidades que ainda continuam sofrendo por falta de água para suas necessidades básicas. A decisão de se construir uma cisterna implica, previamente, em um levantamento dos elementos necessários disponíveis na propriedade ou a serem providenciados, para compor o sistema de captação, armazenamento e manejo de água de chuva. Os elementos essenciais ao sistema de captação de água de chuva (GNADLINGER, 2001):

- Localização: o local selecionado para construção da cisterna deve estar situado longe de lixôes, currais, fossas ou outros pontos de poluiçáo que possam colocar em risco a qualidade da água e/ou comprometer a estrutura da cisterna. A cisterna deve ficar próxima à residência da família ou outras construçóes, para facilitar a colocação das calhas, tubos da área de captação e o próprio acesso à água;

- Tanque de armazenamento: é o reservatório para armazenamento da água da chuva, que pode ser construído utilizando diferentes materiais. Atualmente, o modelo mais 
utilizado é o de placas pré-moldadas, mas outros, como, o de tela de alambrado e cimento já está tendo boa aceitação, por apresentar custos compatíveis e flexibilidade no tamanho do tanque de armazenamento;

- Área de captação: é essencial para captar a chuva precipitada e permitir seu escoamento para o tanque por meio de calhas e tubos. Normalmente, é utilizado como área de captação o próprio telhado das moradias, porém é necessário que, além do tamanho necessário, ele seja regular para captar toda a água da chuva;

- Calhas: toda cisterna deve contar com um sistema de calhas para conduzir a água da área de captação, normalmente o telhado das casas, para o tanque de armazenamento. São necessários alguns cuidados com as calhas para que estas coletem toda a água sem provocar desperdícios. Com as elevadas temperaturas comuns no semiárido, geralmente as calhas de tubos de PVC se deformam, dificultando a captação da água, principalmente quando as chuvas apresentam maior intensidade;

- Cerca de arame: a cisterna deve ser cercada para evitar que pequenos animais (galinhas, cabritos) subam na cobertura e levem sujeiras para dentro da cisterna, como também, acidentes com crianças;

- Calçada: a cisterna deve conter uma calçada para evitar infiltraçóes da água de chuva nas laterais do tanque de armazenamento, que podem comprometer sua estrutura;

- Sangradouro: é essencial a colocação de sangradouro no tanque para permitir o escoamento do excedente da água armazenada;

- Aeradores: a cisterna deve conter tubos em suas paredes, para permitir a renovação do oxigênio dissolvido na água, podendo um desses aeradores ser o próprio sangradouro. Na extremidade desses tubos, deve existir um ralo ou uma tela para evitar a entrada de pequenos animais e materiais grosseiros;

- Bomba: para evitar o contato direto com a água e, em alguns casos, o uso de vasilhas não adequadas para retirar a água, a cisterna deve conter uma bomba manual. A água pode ser 
bombeada diretamente para um reservatório menor localizado na cozinha da casa;

- Porta: a cisterna deve conter uma porta para permitir sua limpeza, a qual deve ser mantida fechada para evitar acidentes com crianças e animais.

Além do Ministério da Integração Nacional, o Ministério do Desenvolvimento Social e Combate à Fome (MDS), por meio da Secretaria Nacional de Segurança Alimentar e Nutricional (SESAN), desde 2003, financia a construção de cisternas de placas de cimento, principalmente na regiáo do Semiárido brasileiro. Trata-se de uma tecnologia simples e de baixo custo, na qual a água da chuva é captada do telhado por meio de calhas e armazenada em um reservatório de 16 mil litros, capaz de garantir água para atender uma família de cinco pessoas em um período de estiagem de aproximadamente oito meses. São três as iniciativas da SESAN que visam à promoção do acesso à água (MDS, 2015):

- Primeira Água (Água para Consumo): implementação de cisternas para captaçáo e armazenamento de água da chuva para o consumo humano, destinadas a famílias que não dispóem de acesso à fonte de água potável, localizadas na zona rural, com renda mensal de até meio salário mínimo por pessoa ou renda mensal total de até três salários mínimos, devendo ser priorizadas aquelas enquadradas nos critérios de elegibilidade do Programa Bolsa Família. Para participarem do Programa, as famílias devem necessariamente estar inscritas no Cadastro Único para Programas Sociais do Governo Federal. O Programa tem como público alvo as famílias rurais de baixa renda localizadas no Semiárido brasileiro, região historicamente caracterizada por longos períodos de estiagem e pelas enormes dificuldades para acessar água em quantidade e qualidade suficiente. Entretanto, a partir de 2011, foram formalizadas parcerias para a construção de cisternas fora da região do Semiárido (Figura 2). 
Figura 2 - Projeto cisterna de água potável localizadas na zona rural do Programa Segunda Água, município de Lagoa do Ouro, Pernambuco, 2015.

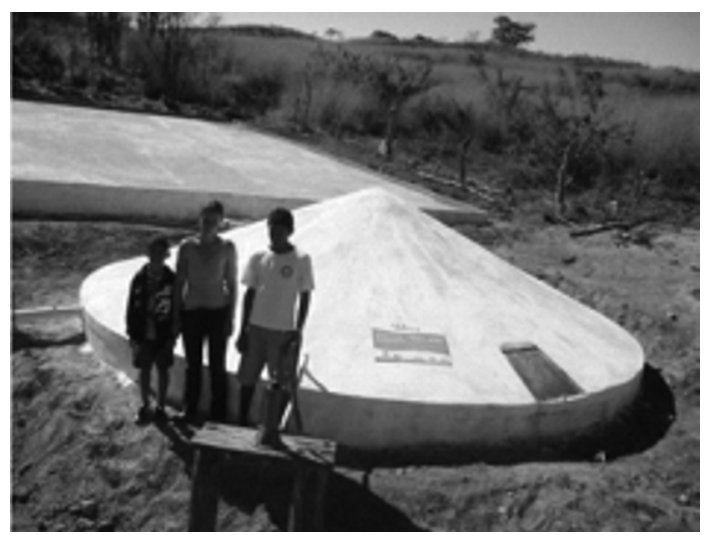

Fonte: Gustavo Mendes Pinheiro (2015).

- Segunda Água (Água para Produção): implementação de tecnologias sociais de captação e armazenamento de água da chuva para a produçáo agropecuária, em propriedades de agricultores familiares do Semiárido brasileiro. Para ter acesso ao programa, a família precisa ter sido beneficiada previamente com a cisterna de água para consumo (Figura 3);

Figura 3 - Visualização da construção das cisternas do Programa Segunda Água, município de Lagoa do Ouro, Pernambuco, 2015.

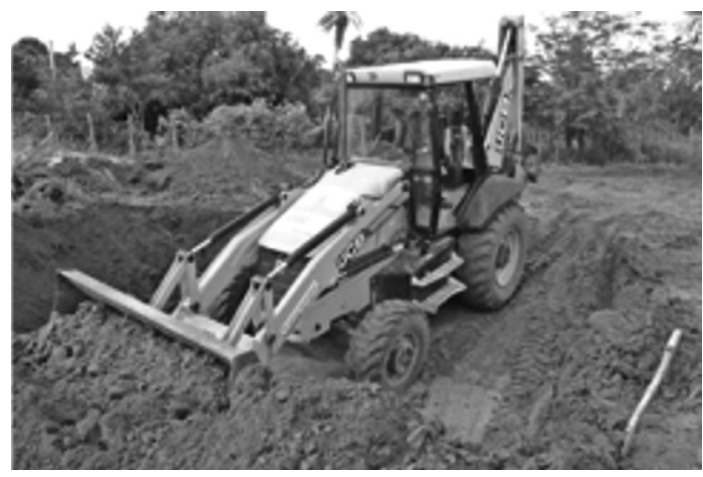

Fonte: Gustavo Mendes Pinheiro (2015). 
- Cisternas nas Escolas: implementação de cisternas para captaçáo e armazenamento de água da chuva para o consumo humano ou para a produçáo de hortas em escolas municipais da zona rural do Semiárido brasileiro (Figura 4);

Figura 4 - Projeto cisterna do Programa Cisterna na Escola, município de Lagoa do Ouro, Pernambuco, 2015.

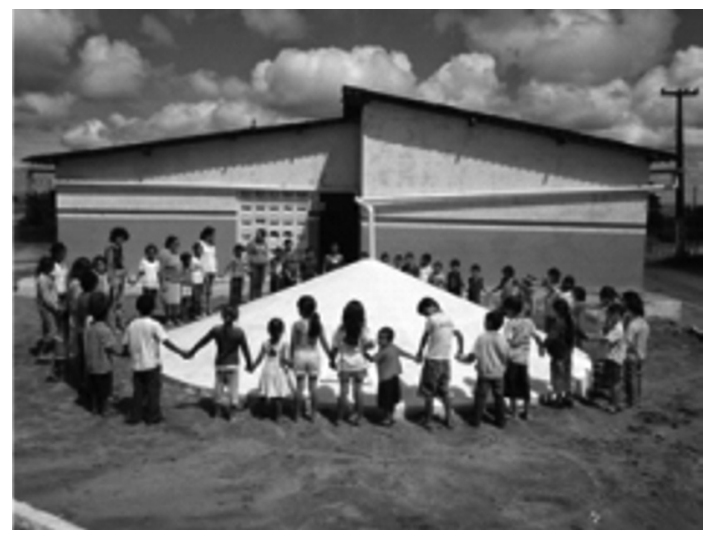

Fonte: Gustavo Mendes Pinheiro (2015).

Vale ressaltar, que os sistemas de captação de água superficial das chuvas parecem, aparentemente, ser um recurso específico de regióes áridas e semiáridas, para resolver parte de seus problemas de escassez de água. Mas as regiôes semiúmidas também sofrem com os momentos de excesso de chuvas, que provocam a degradação dos solos, pelas erosões, principalmente em solos compactados (BARROS, 2003; MARTINS; NOGUEIRA, 2015). Com a infiltração natural prejudicada e o aceleramento das enchentes, a efetividade das chuvas decresce e uma precipitação anual de 700 a $1.000 \mathrm{~mm}$ pode despencar para índices de 500 a $700 \mathrm{~mm}$, agravando a situação de seca e prejudicando a agricultura de sequeiro e a irrigada, pois os lençóis, não se reestabelecendo, prejudicarão também as nascentes, os córregos e as fontes de sustentação de projetos de irrigação (ALBUQUERQUE; DURÃES, 2008; MARTINS; NOGUEIRA, 2015).

\section{Programa da operação carro pipa}

Trata-se de uma operação do governo que visa distribuir água 
potável por meio de carros-pipa para populaçóes situadas nas regióes afetadas pela seca ou estiagem. A ação é uma parceria do Ministério da Integração Nacional, por meio da Secretaria Nacional de Defesa Civil, com o Exército Brasileiro. A execução do programa, incluindo contratação, seleção, fiscalização e pagamento dos pipeiros, é de responsabilidade do Comando de Operaçôes Terrestres do Exército Brasileiro (Coter).

As atividades de cooperação compreendem a distribuição de água potável, preferencialmente por meio de carros pipa, às populaçóes rurais e urbanas atingidas por estiagem, com prioridade para os municípios que se encontram em situação ou estado de calamidade pública, devidamente reconhecida por ato do Governo Federal (Figura 5).

Figura 5 - Distribuição de água potável, por meio de carros pipa, às populações rurais e urbanas do município de Lagoa do Ouro, Pernambuco, 2015.

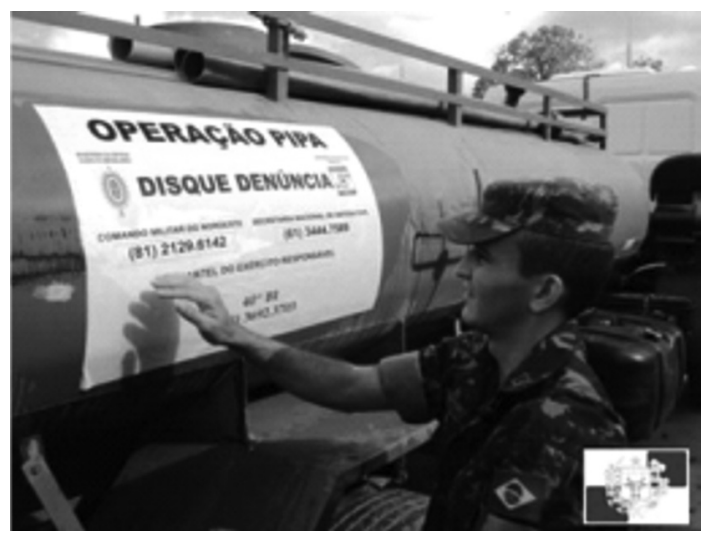

Fonte: Gustavo Mendes Pinheiro (2015).

Programa de aquisição de alimentos (PAA)

A agricultura familiar tem se destacado muito no cenário nacional devido sua importância na garantia de segurança alimentar e nutricional dos brasileiros. Diante disso, políticas públicas estáo sendo direcionadas a esta parcela da sociedade no intuito de aumentar a produção agrícola dos produtores e possibilitar a permanência de 
grande parte das famílias no campo, bem como a continuidade da produção de alimentos que abastece os mercados locais e nacionais.

A agricultura familiar é responsável por abastecer grande parte do mercado consumidor tanto na esfera econômica como social. Dados do Censo Agropecuário de 2006 do IBGE, publicado em 2009, revelam que o setor emprega aproximadamente $75 \%$ da máo-de-obra no campo, sendo diretamente responsável pela segurança alimentar dos brasileiros. Os agricultores familiares produzem $70 \%$ do feijão, $87 \%$ da mandioca, $46 \%$ do milho, $38 \%$ do café, $34 \%$ do arroz, $58 \%$ do leite, $59 \%$ do plantel de suínos, $50 \%$ das aves, 30\% dos bovinos e, ainda, $21 \%$ de trigo consumido no país. O mais interessante é que apesar de ocupar apenas um quarto da área, ou seja, 24,3\% dos estabelecimentos agropecuários totais, a agricultura familiar consegue responder por $38 \%$ do valor da produção, o que equivale em reais a $\mathrm{R} \$ 54,4$ bilhôes (IBGE, 2010).

Dessa forma, o Programa de Aquisição de Alimentos favorece o homem do campo, oferecendo reais oportunidades de comercializaçáo da produção através das compras governamentais, com contratos que sáo elaborados com base na realidade local, minimizando assim muitas vezes, as perdas por falta de canais de comercialização. Por outro lado, o programa garante a segurança alimentar e nutricional com a doaçáo dos produtos da agricultura familiar às entidades públicas locais de assistência social, como creches, escolas, asilos, igrejas e associaçóes comunitárias.

A agricultura familiar enfrenta várias dificuldades que não são fáceis de serem superadas. Apesar de todas as dificuldades e desafios, o pequeno agricultor vem aproveitando a crescente demanda nacional e mundial, principalmente por produtos agroecológicos e orgânicos. É nessa luta que os pequenos agricultores se organizam por meio de associaçóes ou cooperativas, buscando no coletivo a oportunidade de expandir seus negócios, conseguindo melhores preços nos produtos e descobrindo novas oportunidades.

Atualmente, é fácil perceber o quanto esses agricultores, ao se unirem a um sistema associativista, são beneficiados, juntos conseguem maiores destaques no mercado e expandem seus negócios, e com a Lei $11.947 / 09$ os pequenos agricultores podem repassar seus produtos para serem consumidos na merenda escolar, já que ficou estabelecido que 
no mínimo 30\% dos alimentos devem ser adquiridos da agricultura familiar. Essa lei gerou uma grande oportunidade para alavancar a agricultura familiar, uma vez que a compra é garantida pelo governo, porém temos que avançar no planejamento da produção, diminuir as incertezas e abrir novos canais de comercialização (PERACI; BITTENCOURT, 2010).

Para participar do Programa de Aquisição de Alimentos, o produtor deve ser identificado como Agricultor Familiar ou acampado. Essa qualificação é comprovada por meio da Declaração de Aptidão ao PRONAF-DAP.

Segundo a Companhia Nacional de Abastecimento (CONAB $)^{1}$, uma das entidades responsável pela operacionalização do programa em todo o território nacional, o Programa de Aquisição de Alimentos (PAA) é uma das açôes do Fome Zero e tem como objetivos: garantir o acesso aos alimentos em quantidade, qualidade e regularidade necessárias às populações em situação de insegurança alimentar e nutricional; contribuir para formação de estoques estratégicos; e promover a inclusão social no campo, por meio do fortalecimento da agricultura familiar.

Segundo dados da CONAB, desde o início do Programa, foram adquiridos 929.496 mil toneladas de alimentos, comprados pelo Governo Federal de 350 mil agricultores familiares, sendo possível o atendimento de cerca de 15 mil entidades que atendem diretamente pessoas em situação de insegurança alimentar e nutricional. O PAA está presente em aproximadamente 3,5 mil municípios brasileiros. $\mathrm{O}$ Programa é dividido em várias modalidades, que são descritas a seguir:

- Compra: modalidade voltada à aquisição da produção da agricultura familiar em situação de baixa de preço ou em virtude da necessidade de atendimento as demandas por alimentos de populaçóes em condição de insegurança alimentar. Ela é empregada na aquisição de produtos e na movimentação de safras e estoques, adequando a disponibilidade de produtos às necessidades de consumo e cumprindo um importante papel na regulação de preços. $\mathrm{O}$ produto in natura deverá estar limpo, seco, enquadrado nos padróes de identidade e qualidade estabelecidos pelo Ministério da Agricultura, Pecuária e Abastecimento (MAPA). O produto beneficiado
$<$ http://www.conab.gov.br/ conabweb/>. 
deverá ser acondicionado nos padróes estabelecidos pelos Órgáos competentes e entregue nos Polos de Compra (Unidades Armazenadoras próprias ou credenciadas, indicadas pela Conab) ou nos Polos Volantes de Compra;

- Formação de Estoques: criada para propiciar aos agricultores familiares instrumentos de apoio à comercialização de seus produtos alimentícios. A organização de agricultores, juntamente com seus associados, identifica a possibilidade de formação de estoque de determinado produto e submete uma Proposta de Participação à Superintendência Regional à $\mathrm{CONAB}$ mais próxima ou à Delegacia Federal de Desenvolvimento Agrário em seu estado. Esta proposta de participaçáo define qual será o produto a ser estocado, o prazo para a formaçáo de estoque, quais produtos serão adquiridos, seus respectivos preços e quem são os agricultores familiares beneficiados. Sendo aprovada a proposta de participaçáo, a organização emite a CPR e a CONAB disponibiliza recursos financeiros para que a organizaçáo inicie o processo de aquisiçóes de alimentos dos agricultores familiares listados na proposta de participação;

- Programa de Aquisição de Alimentos: o objetivo é propiciar o consumo do leite às famílias, que se encontram em estado de insegurança alimentar e nutricional, e incentivar a produção familiar. O Programa do Leite possui dois focos principais: os segmentos populacionais vulneráveis que recebem o leite gratuitamente e os pequenos produtores familiares. $\mathrm{O}$ Programa é operacionalizado por meio de convênios celebrados entre o Governo Federal, por intermédio do Ministério do Desenvolvimento Social e Combate à Fome, e os Governos Estaduais. O MDS é responsável por garantir entre 80\% e 85\% do valor total do convênio e os governos estaduais aportam uma contrapartida entre $15 \%$ e $20 \%$;

- Compra para doação simultânea: essa modalidade, também conhecida por Compra Direta Local (CDLAF) ou Compra Antecipada Especial com Doação Simultânea (CAEAF), tem como objetivos: a garantia do direito humano à alimentação para pessoas que vivem em situação de vulnerabilidade social 
e/ou de insegurança alimentar; o fortalecimento da agricultura familiar; a geração de trabalho e renda no campo; e a promoção do desenvolvimento local por meio do escoamento da produçáo para consumo, preferencialmente, na regiáo produtora.

Como destacado, cada modalidade possui um teto máximo por agricultor ao ano, porém, os agricultores poderáo participar simultaneamente de duas modalidades, ou seja, a participaçáo conjunta nas modalidades: Formaçáo de Estoque (liquidaçáo física) e Doação Simultânea, totalizando R \$ 8 mil; Compra Direta e Doação Simultânea, totalizando $\mathrm{R} \$ 8$ mil.

Visualiza-se, assim, o PAA Doação Simultânea como o marco zero para o incentivo, a constituição e organização (busca da regularização fiscal, tributária, contábil e legal, além do desenvolvimento de competências administrativas e financeiras) das cooperativas e associaçôes.

Segundo a CONAB, o Grupo Gestor tem a finalidade de definir as medidas necessárias para a operacionalização do Programa de Aquisição de Alimentos, incluindo: sistemática de aquisição dos produtos; preços praticados, que consideram as diferenças regionais e a realidade da agricultura familiar; regiôes prioritárias para implementação do programa; condiçôes de doação dos produtos adquiridos; condiçốes de venda dos produtos adquiridos.

Os gestores executores do Programa são Estados, municípios e CONAB.

Conforme demonstrado até agora, o PAA é um importante instrumento de comercializaçáo da agricultura familiar por meio de suas cooperativas e associaçôes, porém, não se pode perder o foco de sua atenção: combater a pobreza e a insegurança alimentar e nutricional. Sendo assim, os produtos da agricultura familiar, ricos em quantidade e qualidade nutricional são doadas as entidades de assistência social da região próxima onde é produzido, beneficiando, assim, escolas, creches, asilos, igrejas, associaçóes comunitárias, ou seja, a rede de assistência social da regiáo.

A modalidade que mais se destaca é a Formação de Estoques, ela foi criada para propiciar aos agricultores familiares instrumentos de apoio à comercialização de seus produtos. É operada por meio 
de organizações formadas por, no mínimo, 90\% dos sócios/filiados agricultores familiares enquadrados no Pronaf. Esse instrumento disponibiliza recursos financeiros, a partir da emissão da Cédula de Produto Rural (CPR), que é um título representativo de uma obrigação com promessa de entrega de produtos rurais, regulada pela Lei 8.929, de 22 de agosto de 1994.

Para que os grupos adquiram a produção de agricultores familiares sócio/filiados e formem estoques para posterior comercialização, seja pelo beneficiamento e agregaçáo de valor ao produto, seja por sua disponibilização em momentos mais oportunos em termos de preços, o limite de recursos por organização é de $\mathrm{R} \$ 1,5$ milhão. A organização de agricultores, juntamente com seus associados, identifica a possibilidade de formação de estoque de determinado produto e submete uma Proposta de Participação à Superintendência Regional da Companhia Nacional de Abastecimento (CONAB) mais próxima da região. Esta proposta de participaçáo define qual será o produto a ser estocado, o prazo para a formação de estoque, quais produtos seráo adquiridos, seus respectivos preços e quais agricultores familiares serão beneficiados. Aprovada a proposta de participação, a organização emite a CPR e a Conab disponibiliza recursos financeiros para que a organização inicie o processo de aquisição de alimentos dos agricultores familiares listados na proposta de participação.

A CPR tem um prazo de vencimento que é definido em função do produto proposto, mas que náo pode ser superior a 12 meses. Ao final do prazo previsto na Cédula, a organização deverá liquidar a CPR. A liquidação da CPR será realizada financeiramente pelo pagamento do valor recebido, acrescido de encargos de 3\% ao ano, calculados da data da emissão da CPR - Estoque até a data de sua liquidação. A liquidação em produto poderá ser prevista quando de interesse da administração pública. Neste caso, a possibilidade deverá estar descrita na CPR. O mecanismo utilizado pelo Ministério do Desenvolvimento Social e Combate à Fome para a execução desta modalidade é celebração de convênio e repasse de recursos para a Conab.

\section{Estatística dos dados}

A Tabela 1 apresenta a caracterização da amostra de 68 famílias de 
agricultores do município de Lagoa do Ouro, segundo as variáveis socioeconômicas: sexo, faixa etária, grau de escolaridade e renda. Verifica-se que, dos 68 trabalhadores que fizeram parte da pesquisa, $57(83,82 \%)$ são do sexo masculino e $11(16,18 \%)$ do sexo feminino. Quanto ao grau de escolaridade, 51 (72\%) agricultores têm ensino fundamental, $9(13,24 \%)$ apresentam ensino médio, 6 (8,82\%) são analfabetos e apenas $2(2,94 \%)$ possuem o ensino superior. E a maioria dos entrevistados, $48(70,59 \%)$ apresenta renda mensal de 1 a 2 salários mínimos, $14(20,59 \%)$ ganham menos que um salário mínimo e $6(8,82 \%)$ ganham menos que um e/ou superior a três salários mínimos.

Tabela 1 - Distribuição de frequências das variáveis socioeconômicas das famílias de agricultores do município de Lago do Ouro do Estado de Pernambuco, 2015.

\begin{tabular}{lll}
\hline Variáveis & Número de entrevistados & Percentual \\
\hline Sexo & & \\
\hline Feminino & 11 & 16,18 \\
Masculino & 57 & 83.82 \\
\hline Faixa etária & 15 & 22,06 \\
\hline 22 & 10 & 14,71 \\
30 & 43 & 63,24 \\
45 & & \\
\hline Grau de escolaridade & 6 & 8,82 \\
\hline Analfabeto & 51 & 72,00 \\
Ensino fundamental & 9 & 13,24 \\
Ensino médio & 2 & 2,94 \\
Ensino superior & & \\
\hline Renda & 14 & 20,59 \\
\hline$<1$ salário mínimo & 48 & 70,59 \\
1 a 2 salários & 6 & 8,82 \\
$>3$ salários & 68 & 100 \\
Total & & \\
\hline
\end{tabular}

Fonte: Os autores (2015).

Quanto a faixa etária, pela Tabela 1, observa-se que, dos 68 entrevistados, 8 (63,24\%) têm 45 anos; 15 (22,06\%), 22 anos e 10 $(14,71 \%)$ têm 30 anos. Os resultados mostram um percentual muito 
pequeno de jovem na atividade na zonal rural. De acordo com IBGE (2010), a força de trabalho dos jovens brasileiros na faixa etária de 15 a 24 anos, soma 34,1 milhóes de pessoas, correspondendo a 20,1\% do total da população; em áreas rurais vivem 5,9 milhões de jovens, indicando que apenas $17,3 \%$ deles moram na zona rural. Também existem estudos, como os dos pesquisados Carvalho et al. (2009), que indicam que cada vez mais eles trocam o campo pela cidade, este fato evidencia um problema, assim como uma preocupação que começa a se fazer presente no meio acadêmico em relação ao futuro da juventude rural, tais como, a sobrecarga do mercado de trabalho na zona urbana, o desaparecimento da agricultura familiar, a falta de mão-de-obra no campo, entre outras.

A Tabela 2 mostra o resumo estatístico dos trabalhadores rurais em relação às faixas etárias. Verifica-se pela Tabela 2, que a média de idade dos entrevistados é aproximadamente de 37,38 $\pm(9,93)$ anos, variando entre uma faixa etária de 22 a 45 anos.

Tabela 2 - Estatística da variável idade das famílias de agricultores do município de Lago do Ouro do Estado de Pernambuco, 2017.

\begin{tabular}{cccccc}
\hline Variável & $\begin{array}{c}\text { Número } \\
\text { entrevistados }\end{array}$ & Média & $\begin{array}{c}\text { Desvio- } \\
\text { padrão }\end{array}$ & Máximo & Mínimo \\
\hline $\begin{array}{c}\text { Idade } \\
\text { (anos) }\end{array}$ & 68 & 37,38 & 9,93 & 45 & 22 \\
\hline
\end{tabular}

Fonte: Os autores (2015).

Verifica-se pela Tabela 3, que, dos 68 produtores rurais entrevistados quanto à origem da água para o consumo humano, 41 (60,29 \%) deles usam água do carro pipa, 11 (16,18\%) afirmaram receber água tratada das barragens da Companhia Pernambucana de Saneamento de Garanhuns - COMPESA (Barragens do Riacho da Palha, da Cova Triste e do Distrito de Igapó), 8 (11,76 \%) retiram água de cisternas para consumo, $4(5,88 \%)$ de poços e $3(4,41 \%)$ possuem a origem da água vinda de barreiros. 
Tabela 3 - Distribuição absoluta dos percentuais quanto à origem de água para consumo humano e atividades agrícolas pelos Agricultores rurais do município de Lago do Ouro do Estado de Pernambuco, 2015.

\begin{tabular}{lcc}
\hline Origem da água & Número de entrevistados & Percentual \\
\hline Consumo humano & 1 & \\
Riachos & 3 & 1,47 \\
Barreiros & 8 & 4,41 \\
Cisternas & 4 & 11,76 \\
Poços & 41 & 5,88 \\
Carro pipa & 11 & 60,29 \\
Água tratada das Barragens ${ }^{2}$ & & 16,18 \\
Atividades agrícolas & 11 & \\
Riachos & 21 & 16,18 \\
Barreiros & 9 & 30,88 \\
Cisternas & 27 & 13,24 \\
Poços & 68 & 39,71 \\
Total & & 100 \\
\hline
\end{tabular}

Fonte: Os autores (2015).

Observa-se pela Tabela 3, que, dos 68 produtores rurais entrevistados com relação à origem da água para atividades agrícolas em sua propriedade rural, 27 (39,71 \%) deles usam água oriunda de poços, $21(30,88 \%)$ apresentam a fonte de água de sua propriedade vinda de barreiros, $11(16,18)$ utilizam água para atividades agrícolas de riachos e apenas $9(13,24 \%)$ utilizam as provenientes de cisternas. Não foi encontrado nenhum agricultor rural que utilizasse água trata pela COMPESA para fins de irrigação. É importante salientar que o uso das técnicas adequadas, associado ao uso dos recursos hídricos existentes, poderia ser de crucial importância para o desenvolvimento econômico local.

\section{DISCUSSÃO}

As ações governamentais implementadas na região semiárida do Nordeste, via programas de construção de cisternas rurais e outras fontes de captação e acumulação de água, embora tenham contribuído, 
em parte, para amenizar os problemas da falta de água para consumo das populaçóes rurais atendidas por esses programas, ainda não foram suficientes para promover transformaçóes na regiáo, pois a cada novo período de estiagem que ocorre na região, as calamidades provocadas pelas secas voltam a trazer transtornos para os seus habitantes.

No Município de Lagoa do Ouro, foram observadas famílias que possuem cisternas em suas residências para captação e armazenamento de água de chuva. Dessas cisternas, verificou-se que grande parte é do tipo tanque (cisterna de tijolo) e um pequeno número de placas, construídas pela Prefeitura Municipal e pelo Programa Água para Todos do Governo Federal. As cisternas de placas existentes na comunidade têm capacidade para 16.000 litros cada, enquanto as cisternas tipo tanque têm capacidade média de 6.500 litros.

Há diversos tipos de cisternas que podem ser construídas pelos agricultores com ajuda do Governo Federal em parceria com a Prefeitura Municipal de Lagoa do Ouro, como cisternas de placas de cimento, cisternas de tela-cimento, cisternas de tijolos, cisternas de ferro cimento, cisternas de cal e cisternas de plástico. Contudo, as cisternas rurais construídas pelos agricultores, sem a participação de programas governamentais, geralmente são de tijolos e, algumas vezes, mais caras que uma cisterna de placa que pode ser construída para a acumulação de 10.000 litros de água por $\mathrm{R} \$ 219,00$.

Pode-se constatar que das 68 famílias entrevistadas no período de janeiro a dezembro de 2015, 25\% (11,76 + 13,24\%) delas acumularam água da chuva nas cisternas no mês de janeiro de 2015 , contudo, já a partir de junho, algumas cisternas da comunidade foram abastecidas com água de carro-pipa fornecido pela Prefeitura Municipal de Lagoa do Ouro e outras vezes adquirido pelos agricultores ao preço de $\mathrm{R} \$$ 70,00 por aproximadamente, 10.000 litros de água. Vale ressaltar que o emprego da água de origem das cisternas para outros fins diminui a garantia de água de boa qualidade para o período de estiagem. A água acumulada nos barreiros foi utilizada por 35,39\% (4,41 + 30,39 \%) das famílias dos agricultores, para beber, atividades agrícolas e consumo dos animais. Para as famílias que não tinham cisternas a água foi obtida de caldeiróes, barreiros e carros-pipas durante todo o ano.

A água de carro-pipa foi utilizada, em média, por 60,29\% das famílias das comunidades. Em algumas famílias as cisternas são abastecidas por 
carros-pipa, desviando-se do principal objetivo de sua construção, que é o de armazenar água de chuva, de melhor qualidade para o consumo humano. No geral, o uso de água de carro-pipa ocorre quando as águas de chuva armazenadas não são suficientes para satisfazer a demanda familiar, seja porque as chuvas do período foram escassas ou porque a área de escoamento é reduzida ou porque a família tem numerosos membros que consomem mais água do que é possível armazenar no sistema instalado.

Os programas do Governo Federal e outras fontes de captação e acumulação de água da chuva no semiárido do Nordeste brasileiro, embora tenham contribuído, em parte, para o alívio das populaçóes rurais, não têm capacidade para captar um volume de água suficiente para atender as necessidades dos agricultores, pois mesmo em anos de precipitação considerada acima do normal, a estiagem que ocorre no período de seca gera calamidades para famílias das zonas rurais provocando graves transtornos para seus habitantes.

\section{CONSIDERAÇÕES FINAIS}

Durante todos os trabalhos desenvolvidos na Secretaria de Agricultura do Município de Lagoa do Ouro do Estado de Pernambuco, pudemos acompanhar trabalhos em diversas áreas da agricultura, principalmente como os programas do Governo Federal e estadual são executados, e como são importantes para o desenvolvimento da localidade.

A atuação do projeto foi de forma mais significativa com os seguintes programas: Programas Água para Todos, Operação Carro-pipa e o Programa de Aquisição de Alimentos. Mesmo com todo o empenho da Secretaria, os benefícios ofertados ainda são pequenos em recursos financeiros e tecnológicos principalmente, como o número de máquinas e equipamentos agrícolas que poderiam complementar os trabalhos prestados, beneficiando toda a região. E sem dúvidas, contribuirá positivamente para a solução do problema de falta de água no Semiárido, porém, devido aos problemas de gestão que emparelha a maior parte dos programas sociais brasileiros, esta solução provavelmente levará mais outro século para acontecer.

O projeto proporcionou a ampliação da vivência nas atividades 
agrícolas e a oportunidade de conviver com a realidade social, promovendo a vivência prática para os discentes participantes do projeto e fomentando a integração dos programas sociais do Governo Federal das comunidades rurais atendidas com os alunos do curso de Agronomia. Assim, se pode afirmar que a captaçáo e o armazenamento da água oriunda da precipitação é uma forma de conscientização que ajuda a preservar esse recurso natural, utilizando-a de maneira racional, contribuindo para preservação da natureza, para redução de custos da propriedade e água com padróes mínimos de qualidade. Diversas práticas de cultivo associadas aos sistemas de captação de água das chuvas são alternativas viáveis para uso no meio rural, quando se visa produção sustentável.

Entretanto pode-se concluir que as açóes governamentais implementadas na regiáo semiárido do Nordeste, via programas de construção de cisternas rurais e outras fontes de captação e acumulaçáo de água, embora tenham contribuído, em parte, para o alívio das populaçóes rurais atendidas por esses programas, ainda náo são suficientes para a grande transformação da regiâo, que é a convivência com a seca, pois a cada novo período de estiagem que ocorre na região, as calamidades provocadas pela seca voltam a trazer transtornos para os habitantes do semiárido nordestino.

\section{REFERÊNCIAS}

ALBUQUERQUE, P. E. P.; DURĀES, F. O. M. Uso e manejo de irrigaçáo. Brasília, DF: Embrapa Informação Tecnológica, 2008. $508 \mathrm{p}$.

BARBETTA, P. A. Estatística aplicada às ciências sociais. 4. ed. Florianópolis: UFSC, 2001. 838 p.

BARROS, L. C. de. Barraginhas para captação de água de chuvas, recuperação de áreas degradadas e regeneração de mananciais - A, B, C, D, E - Fases da mobilização. In: SIMPÓSIO BRASILEIRO DE CAPTAÇĀO E MANEJO DE ÁGUA DE CHUVA, 4., 2003, Juazeiro. Anais... Juazeiro, 2003.

BRITO, L. T. de L. Alternativa tecnológica para aumentar a disponibilidade de água no semiárido. Revista Brasileira de 
Engenharia Agrícola e Ambiental, Campina Grande, v. 3, n. 1, p. 111-115, 1999. doi: https://doi.org/10.1590/1807-1929/agriambi. v3n1p111-115.

CARVALHO, D. M. et al. Perspectivas dos jovens rurais: campo versus cidade. In: 47 CONGRESSO DA SOCIEDADE BRASILEIRA DE ECONOMIA, ADMINISTRAÇÃO E SOCIOLOGIA RURAL, 47., 2009, Porto Alegre, 26 a 30 de julho de 2009. Anais... Porto Alegre, 2009.

CODEVASF - Coordenadoria de Desenvolvimento dos Vales do São Francisco. Codevasf beneficia mais de $\mathbf{4 2}$ mil famílias com cisternas em Pernambuco, 2015. Disponível em: <http://www.brasil.gov.br/ infraestrutura/2015/01/codevasf-beneficia-mais-de-42-mil-familiascom-cisternas-em-pernambuco>. Acesso em: 19 maio 2017.

GIL, A. C. Como elaborar projetos de pesquisa. 3. ed. São Paulo: Atlas, 2000. 176 p.

GNADLINGER, J. A contribuição da captação de água de chuva para o desenvolvimento sustentável do semi-árido brasileiro: uma abordagem focalizando o povo. In: SIMPÓSIO BRASILEIRO DE CAPTAÇÃO DE ÁGUA DE CHUVA NO SEMI ÁRIDO, 3., 2001. Campina Grande. Anais... Campina Grande , 2001.

IBGE - Instituto Brasileiro de Geografia e Estatística. Levantamento sistemático da produção agrícola (LSPA). 2010. Disponível em: <http://www.ibge.gov.br/home/estatistica/indicadores/agropecuaria/ lspa>. Acesso em: 19 maio 2016.

Cidades. 2015. Disponível em: < http://www.cidades.ibge.gov.br/xtras/ perfil.php?lang=\&codmun=260600\&search=pernambuco $\mid$ garanhuns $>$. Acesso em: 15 jan. 2015.

LIBERAL, G. S. et al. Aproveitamento dos rejeitos da dessalinização: a captação de água de chuva - base para viabilização do semiárido brasileiro. In: SIMPÓSIO SOBRE CAPTAÇÃO DE ÁGUA DE CHUVA NO SEMIÁRIDO BRASILEIRO, 1., 1997, Petrolina. Anais... Petrolina: Embrapa Semi-Árido/IRPAA/IRCSA, 1999. 186 p.

LOPES, P. R. C. et al. Captação e armazenamento de água de chuva no semiárido do Nordeste do Brasil. Embrapa Semiárido. In: XIV 
REUNIÃO BRASILEIRADE MANEJO E CONBSERVAÇÃO DO

SOLO E DA AGUA. Cuiabá, MT, Brasil, Anais... Cuiabá: SBCS/ UFMT-DSER, 2002. CD-ROM.

MACEDO, O. M. A. Convivência com o Semiárido: desenvolvimento regional e configuração do local no projeto do IRPAA. 2004. Dissertação (Mestrado) - Universidade Federal de Pernambuco, Recife, 2004.

MARTINS, C. A. S.; NOGUEIRA, N. O. Captação de água da chuva em propriedades rurais. Nucleus, v. 12, n. 1, abr. 2015.

MDS - Ministério do Desenvolvimento Social e Combate à Fome. Secretaria Nacional de Segurança Alimentar e Nutricional. 2015. Disponível em: <http://www.mds.gov.br/segurancaalimentar/ programa-cisternas>. Acesso em: 15 dez. 2016.

PERACI, A. S.; BITTENCOURT, G. A. Agricultura familiar e os programas da garantia de preços no Brasil: o Programa de Aquisição de Alimentos (PAA). In: SILVA, J. G.; DEL GROSSI, M. E.; FRANÇA, C. G. de (Orgs.) Fome Zero: a experiência brasileira. Brasília, DF: MDS, 2010. p. 191-222.

PRINZ, D. Water harvesting for afforestation in dry areas. Universität Karlsruhe, Germany, 2001.

Submetido em 27 de janeiro de 2017.

Aprovado em 30 de junho de 2017. 